\title{
BMJ Open Trends in the incidence and mortality of multiple births by socioeconomic deprivation and maternal age in England: population-based cohort study
}

\author{
Lucy K Smith, Bradley N Manktelow, Elizabeth S Draper, Elaine M Boyle, \\ Samantha J Johnson, David J Field
}

To cite: Smith LK, Manktelow BN, Draper ES, et al. Trends in the incidence and mortality of multiple births by socioeconomic deprivation and maternal age in England: population-based cohort study. BMJ Open 2014:4:e004514.

doi:10.1136/bmjopen-2013004514

- Prepublication history for this paper is available online. To view these files please visit the journal online (http://dx.doi.org/10.1136/ bmjopen-2013-004514).

Received 20 November 2013 Revised 12 March 2014 Accepted 13 March 2014

CrossMark

Department of Health

Sciences, University of Leicester, Leicester, UK

Correspondence to Dr Lucy K Smith; Iks1@leicester.ac.uk

\section{ABSTRACT}

Objective: To investigate temporal trends in multiple birth rates and associated stillbirth and neonatal mortality by socioeconomic deprivation and maternal age in England.

Design: Population cohort study.

Setting: England.

Participants: All live births and stillbirths (1 January 1997 to 31 December 2008).

Main outcome measures: Multiple maternity rate, stillbirth and neonatal death rate by year of birth, decile of socioeconomic deprivation and maternal age.

Results: The overall rate of multiple maternities increased over time $(+0.64 \%$ per annum $95 \% \mathrm{Cl}$ $(0.47 \%$ to $0.81 \%))$ with an increase in twin maternities (+0.85\% per annum $95 \% \mathrm{Cl}(0.67 \%$ to $1.0 \%))$ but a large decrease in triplet and higher order maternities (-8.32\% per annum $95 \% \mathrm{Cl}(-9.39 \%$ to $-7.25 \%)$ ). Multiple maternities were significantly lower in the most deprived areas, and this was most evident in the older age groups. Women over 40 years of age from the most deprived areas had a $34 \%$ lower rate of multiple births compared with similar aged women from the most deprived areas (rate ratio (RR) $0.6695 \% \mathrm{Cl}$ (0.61 to 0.73$)$ ). Multiple births remain at substantially higher risk of neonatal mortality (RR $6.3095 \% \mathrm{Cl}(6.07$ to 6.53)). However, for stillbirths, while twins remain at higher risk, this has decreased over time (1997-2000: RR 2.89 (2.69 to 3.10); 2005-2008: RR $2.2295 \% \mathrm{Cl}$ (2.06 to 2.40)). Socioeconomic inequalities existed in mortality for singletons and multiple births.

Conclusions: This period has seen increasing rates of twin pregnancies and decreasing rates of higher order births which have coincided with changes in recommendations regarding assisted reproductive techniques. Socioeconomic differences in multiple births may reflect differential access to these treatments. Improved monitoring of multiple pregnancies is likely to have led to the reductions in stillbirths over this time.

\section{INTRODUCTION}

Recent decades have seen a major increase in multiple births rates globally. ${ }^{1}$ In England and Wales, twin maternities increased from

\section{Strengths and limitations of this study}

This study uses national routinely collected data which have the advantage of being readily available and having national coverage. Our statistical analyses allowed the exploration of time trends and interactions between risk factors, information which is not available from standard published tables on multiple births in the UK.

- These national data lack detail on the chorionicity of the multiple births, gestation or assisted reproductive technologies which prevented further exploration of the impact of these factors on multiple birth incidence and mortality. Data collection on these factors started in 2013 in the UK allowing a more detailed understanding of this in the future.

- While we could not link births from the same maternity, our sensitivity analyses comparing the overall estimated number of multiple maternities with published data showed that this method estimated the overall number to within $1 \%$ of the actual rates and so any impact on the findings presented here is likely to be small.

$0.9 \%$ of deliveries in the early 1980 s to $1.4 \%$ in the late $1990 \mathrm{~s},{ }^{23}$ and this is similar to patterns described outside the UK. ${ }^{4}{ }^{5}$ Most noticeably, there were dramatic changes in England for triplet and higher order maternities with major increases from around $0.01 \%$ of deliveries in the 1980 s peaking at $0.05 \%$ in the late 1990 s. Recent evidence indicates a reversal of this trend with rates of triplet pregnancies declining until $2001^{6}$ to $0.04 \%$.

These rapid temporal increases in multiple births are of key concern. Multiple births have a large impact on healthcare costs because of the increased health risk compared with singletons. Despite improvements in perinatal outcomes in recent decades, twin and triplet pregnancies are associated 
with increased risks of obstetric and neonatal complications including preterm birth, ${ }^{7}$ intrauterine growth restriction, ${ }^{8}$ twin-twin transfusion syndrome ${ }^{9}$ and congenital abnormalities. ${ }^{10}$ Consequently, while multiple births account for only a small percentage of births (3\% in England and the USA), these infants are at greatly increased risk of adverse outcomes, with $16 \%$ of neonatal deaths in England being multiple births. ${ }^{2} 11$

The increase seen in the rate of multiple births is generally attributed to the introduction and rise in access to assisted reproductive technologies (ART) and increasing maternal age. However, there is little research assessing whether the widespread increase in the use of ART has led to changes in the rate of multiple births across all socioeconomic groups due to differential access to treatment. Research in the late $1990 \mathrm{~s}^{12}$ highlighted higher rates of multiple births to higher social class families where the father had a higher social class, but these analyses excluded those born to single or unemployed parents, thus, potentially underestimating any socioeconomic inequalities. While standard tables on multiple births and associated mortality are available nationally (http://www.ons.gov.uk), they do not offer the ability to explore the inter-relationships between factors such as maternal age and socioeconomic deprivation over time.

We combine national data to update temporal trends and explore the effects of socioeconomic deprivation and maternal age on twin and higher order multiple maternity rates in England and associated stillbirth and neonatal mortality.

\section{METHODS}

Data were obtained on all live births to mothers resident in England between 1 January 1997 and 31 December 2008 by multiplicity of birth, year of birth, maternal age, birth weight, sex, primary care trust (PCT) and deprivation decile (using the area level index of multiple deprivation $2004^{13}$ from the UK Office for National Statistics (ONS; http://www.statistics.gov.uk)). Information on stillbirths and neonatal deaths (death of a live-born baby within the first 28 days of life) for the same period were obtained from the Centre for Maternal Child Enquiries (CMACE; http://www.cmace.org.uk), which collected neonatal mortality data as part of its national perinatal mortality surveillance work funded by the National Patient Safety Agency. Data included cause of death, gestational age and super output area of mother's residence (geographical populations of approximately 1500 residents).

\section{Estimating the number of maternities}

The birth data we obtained from ONS did not allow multiple births from a single maternity to be linked together. Therefore, the number of multiple maternities (multiple pregnancies resulting in at least one registered live birth or stillbirth) had to be estimated. The number of twin maternities was estimated by calculating the total number of live births and stillbirths recorded as being from twin maternities by PCT, mother's age group (5-year bands), year of birth and deprivation decile, resulting in 99660 categories overall. The number of twin births in each category was then divided by two to give the number of twin maternities (rounded up to the nearest whole number to include maternities where one fetus in the pregnancy ended in an unrecorded fetal loss). Similarly, for the data on triplets and higher order multiple births, the number of maternities was taken as $1 / 3$ of the births from higher order multiple pregnancies (again rounded up to the nearest whole number). Our estimated total number of multiple maternities differed by only $1 \%$ from the published total number of multiple maternities in England for $1997-2001^{6}$ (ONS), indicating any underestimation of multiple maternities was negligible.

We measured socioeconomic deprivation by using an area level measure of deprivation, the index of multiple deprivation for $2004^{13}$ at the super output area level. This measure of multiple deprivation is made up of seven domain indices at the super output area level, which relate to income, employment, health and disability, education, skills and training, barriers to housing and services, and living environment and crime. Super output areas are the smallest areas for which these deprivation data are available and are based on census geography with around 1500 residents in each; although some degree of heterogeneity will exist within them, the small size of the areas limits this. We ranked all super output areas in England by deprivation score and divided them into 10 groups with approximately equal populations of births: 1 (least deprived) to 10 (most deprived). If neonatal mortality was the same for all deprivation groups, a similar proportion of neonatal deaths would be expected in each 10th.

\section{Statistical analysis}

The number of maternities by multiplicity of birth (singleton, twin, triplet and higher order) and the rate of multiple maternities were calculated by maternal age (5-year bands), deprivation decile and year of birth. Poisson regression models were then used to assess trends in the rate of multiple maternities by maternal age and deprivation decile over time. Interactions were fitted to assess time trends and maternal age differences in the rate of multiple births by socioeconomic deprivation.

The number of births was then used to calculate stillbirth and neonatal mortality rates by multiplicity of birth, deprivation decile, year of birth and maternal age. Poisson regression models including interactions were used to explore trends over time by socioeconomic deprivation and maternal age. Analyses were undertaken using STATA V.12.

\section{RESULTS}

There were 7278707 live-births and 32475 stillbirths over the 12-year period, of which 210446 births were twins $(29 / 1000)$ and 6795 from a triplet or higher order 
pregnancy (1/1000). This corresponded to 7202637 estimated maternities, of which 106310 were twin maternities $(15 / 1000)$ and 2386 triplet or higher order maternities $(3 / 10000)$.

\section{Trends in the incidence of multiple maternities}

The rate of multiple maternities, that is, the proportion of all maternities resulting in a multiple birth increased over the 12 -year time period by $0.64 \%$ per year $(95 \%$ CI $(0.47 \%$ to $0.81 \%))$ from $14.7 / 1000$ maternities in 1997 to $15.6 / 1000$ in 2008 (table 1). These trends differed between twins and higher order multiple births (table 1). Univariable analyses showed that the rate of twin maternities increased over time by $0.85 \%$ per year $(95 \%$ CI $(0.67 \%$ to $1.00 \%))$, while in contrast, there was a consistent year-on-year reduction of $8.32 \%$ per year $(95 \%$ CI $(-7.25 \%$ to $-9.39 \%))$ in the proportion of triplet and higher order maternities with rates halving over the 12-year period.

The increase in multiple maternities over time was strongly associated with changing patterns of maternal age (table 2). There was a steady overall increase in the proportion of all maternities among women aged over 35 years, rising from $13.7 \%$ in 1997 to $20.1 \%$ in 2008 . Since the rate of multiple maternity increased with increasing maternal age (figure 1), this led to an increase in multiple maternities. Furthermore, the data also indicated that for women aged 40 years and over, the rate of multiple maternities increased over the period of the study, while for all other age groups there was little change over time. On the basis of the Poisson multivariable model exploring year of birth and maternal age, women aged 40 years and over were 2.95 times more likely to deliver twins than women under 20 years in 1997 and this increased to 3.57 times more likely in 2007 (1997: rate ratio (RR) 2.95; 95\% CI (2.69 to 3.22); and in 2008: RR 3.57; 95\% CI (3.30 to 3.86)) $(p<0.0001)$. For triplets and higher order births, women aged 40 years and over were more than 10 times more likely to deliver triplets or higher order multiples than women under 20 (RR 10.12; 95\% CI (7.04 to 14.56)), but numbers were too small to assess trends over time.

Exploring rates by socioeconomic deprivation showed that the rates of multiple maternities decreased with increasing deprivation from $18 / 1000$ in the least deprived decile to 12.1 in the most deprived decile (table 3). Poisson univariable regression models showed a 33\% lower rate of multiple pregnancies in the most deprived decile compared with the least deprived (RR $0.67 ; 95 \%$ CI $(0.65$ to 0.69$))$. The pattern when based on just twin maternities was similar (RR $0.68 ; 95 \%$ CI (0.65 to 0.69$)$ ), but a wider gap was seen for triplet and higher order maternities (RR $0.46 ; 95 \%$ CI $(0.38$ to $0.56)$ ). Multivariable analyses showed that the deprivation gap for all multiple births did not significantly change over time $(p=0.97)$ but did vary with maternal age (table $4 ; \mathrm{p}<0.0001)$. There was no evidence of a difference in multiple maternity rates in women under
20 years of age (RR comparing most and least deprived deciles: 1.03 ; $95 \%$ CI $(0.92$ to 1.17$))$, but there was a widening gap with increasing age (over 40 years RR 0.66; $95 \%$ CI $(0.61$ to 0.73$)$ ) (figure $2 \mathrm{~A}, \mathrm{~B})$. Looking at these patterns by type of multiple birth showed no evidence of a change in the deprivation effect over time for twins. However, there was a significant reduction in the deprivation gap for triplet and higher order pregnancies from a $63 \%$ reduced risk of triplets for women from the most deprived decile compared with the least deprived in 1997-2000 compared with a $44 \%$ reduced risk in 20052008.

Trends in stillbirth and neonatal death among multiple births

Tables 4 and 5 show the crude rates for stillbirth and neonatal death by multiplicity for year of birth and deprivation, while table 6 shows the rates from the multivariable model including time period and deprivation decile. Rates of stillbirth were over twice as high in twin births as in singletons (RR 2.49; 95\% CI (2.39 to 2.60)) and four times higher in triplets and higher order births (RR 4.40; 95\% CI (3.70 to 5.24)). The number of triplet and higher order births were too small for more detailed analysis and so models were fitted for singletons and twin births only. While stillbirth rates among singletons showed no evidence of change over time (table 4), there was a dramatic reduction in stillbirth rates among twins. Consequently, while in 1997-2000, twins were at 2.89 (95\% CI (2.69 to 3.10)) times the risk of stillbirth compared with singletons; this had reduced to 2.22 (95\% CI (2.06 to 2.40)) by 2005-2008. Babies born to mothers from the most deprived decile showed higher rates of stillbirth for singletons (RR 1.94; 95\% CI (1.84 to 2.05$)$ ) and twins (RR 1.54; 95\% CI (1.28 to 1.85$)$ ) compared with babies born to mothers from the least deprived decile, but there was no evidence of a deprivation gap for triplets and higher order births $(0.88 ; 95 \%$ CI $(0.39$ to 2.00$))$. While the relative deprivation gap for stillbirth appears narrower for twins than singletons (1.54 compared with 1.94), the absolute deprivation gap in stillbirth is much wider for twins due to the higher mortality. For twin births, there were 47.0 additional stillbirths per 10000 births in the most deprived decile compared with the least deprived decile, while for singletons this gap was 27.9 additional stillbirths per 10000 births. There was no evidence of a differential improvement over time in the rate of stillbirths among multiple births between deprivation deciles. Neonatal mortality was considerably higher for twins (RR 6.30; 95\% CI (6.07 to 6.53)) and triplets (RR 15.47; 95\% CI (13.73 to 17.43)) compared with singletons. Mortality increased with increasing deprivation for singletons (most deprived decile vs least deprived decile RR 2.41; 95\% CI (2.25 to $2.58)$ ) and twin births (RR 1.93; 95\% CI (1.66 to 2.26)) but not for triplets (RR 0.89; $95 \%$ CI (0.51 to 1.56$)$ ). Neonatal mortality rates improved over time for all births (tables 4 and 6), with a greater percentage 
Table 1 Number of singleton and multiple maternities and rate per 1000 maternities by year of birth and rate ratio compared with 1997, England 1997-2008

\begin{tabular}{|c|c|c|c|c|c|c|c|c|c|c|c|}
\hline & \multirow{3}{*}{$\begin{array}{l}\text { All } \\
\text { maternities } \\
\mathrm{N}\end{array}$} & \multirow{3}{*}{$\begin{array}{l}\text { Singleton } \\
\text { maternities } \\
\mathbf{N}\end{array}$} & \multicolumn{9}{|c|}{ Multiple maternities } \\
\hline & & & \multicolumn{3}{|c|}{ All multiples } & \multicolumn{3}{|l|}{ Twins } & \multicolumn{3}{|c|}{ Triplets and above } \\
\hline & & & $\overline{\mathbf{N}}$ & Rate/1000 & Rate ratio & $\overline{\mathbf{N}}$ & Rate/1000 & Rate ratio & $\overline{\mathbf{N}}$ & Rate/1000 & Rate ratio \\
\hline \multirow[t]{2}{*}{1997} & 602383 & 593558 & 8825 & 14.7 & 1 & 8526 & 14.2 & 1 & 299 & 0.50 & 1 \\
\hline & & & & 14.3 to 15.0 & - & & 13.9 to 14.5 & - & & 0.44 to 0.56 & - \\
\hline \multirow[t]{2}{*}{1998} & 596232 & 587530 & 8702 & 14.6 & 1.00 & 8399 & 14.1 & 1.00 & 303 & 0.51 & 1.02 \\
\hline & & & & 14.3 to 14.9 & 0.97 to 1.03 & & 13.8 to 14.4 & 0.97 to 1.03 & & 0.45 to 0.57 & 0.87 to 1.20 \\
\hline \multirow[t]{2}{*}{1999} & 583714 & 575172 & 8542 & 14.6 & 1.00 & 8286 & 14.2 & 1.00 & 256 & 0.44 & 0.88 \\
\hline & & & & 14.3 to 14.9 & 0.97 to 1.03 & & 13.9 to 14.5 & 0.97 to 1.03 & & 0.39 to 0.50 & 0.75 to 1.04 \\
\hline \multirow[t]{2}{*}{2000} & 567157 & 558765 & 8392 & 14.8 & 1.01 & 8136 & 14.3 & 1.01 & 256 & 0.45 & 0.91 \\
\hline & & & & 14.5 to 15.1 & 0.98 to 1.04 & & 14.0 to 14.7 & 0.98 to 1.04 & & 0.40 to 0.51 & 0.77 to 1.07 \\
\hline \multirow[t]{2}{*}{2001} & 558109 & 549757 & 8352 & 15.0 & 1.02 & 8140 & 14.6 & 1.03 & 212 & 0.38 & 0.77 \\
\hline & & & & 14.6 to 15.3 & 0.99 to 1.05 & & 14.3 to 14.9 & 1.00 to 1.06 & & 0.33 to 0.43 & 0.64 to 0.91 \\
\hline \multirow[t]{2}{*}{2002} & 560122 & 551598 & 8524 & 15.2 & 1.04 & 8357 & 14.9 & 1.05 & 167 & 0.30 & 0.60 \\
\hline & & & & 14.9 to 15.5 & 1.01 to 1.07 & & 14.6 to 15.2 & 1.02 to 1.09 & & 0.26 to 0.35 & 0.50 to 0.73 \\
\hline \multirow[t]{2}{*}{2003} & 584180 & 575394 & 8786 & 15.0 & 1.03 & 8649 & 14.8 & 1.05 & 137 & 0.23 & 0.47 \\
\hline & & & & 14.7 to 15.4 & 1.00 to 1.06 & & 14.5 to 15.1 & 1.02 to 1.08 & & 0.20 to 0.28 & 0.39 to 0.58 \\
\hline \multirow[t]{2}{*}{2004} & 601147 & 591971 & 9176 & 15.3 & 1.04 & 9020 & 15.0 & 1.06 & 156 & 0.26 & 0.52 \\
\hline & & & & 15.0 to 15.6 & 1.01 to 1.07 & & 14.7 to 15.3 & 1.03 to 1.09 & & 0.22 to 0.30 & 0.43 to 0.63 \\
\hline \multirow[t]{2}{*}{2005} & 606808 & 597618 & 9190 & 15.1 & 1.03 & 9043 & 14.9 & 1.05 & 147 & 0.24 & 0.49 \\
\hline & & & & 14.8 to 15.5 & 1.00 to 1.06 & & 14.6 to 15.2 & 1.02 to 1.08 & & 0.21 to 0.28 & 0.40 to 0.59 \\
\hline \multirow[t]{2}{*}{2006} & 628974 & 619205 & 9769 & 15.5 & 1.06 & 9620 & 15.3 & 1.08 & 149 & 0.24 & 0.48 \\
\hline & & & & 15.2 to 15.8 & 1.03 to 1.09 & & 15.0 to 15.6 & 1.05 to 1.11 & & 0.20 to 0.28 & 0.39 to 0.58 \\
\hline \multirow[t]{2}{*}{2007} & 648385 & 638315 & 10070 & 15.5 & 1.06 & 9935 & 15.3 & 1.08 & 135 & 0.21 & 0.42 \\
\hline & & & & 15.2 to 15.8 & 1.03 to 1.09 & & 15.0 to 15.6 & 1.05 to 1.11 & & 0.18 to 0.25 & 0.34 to 0.51 \\
\hline \multirow[t]{2}{*}{2008} & 665426 & 655058 & 10368 & 15.6 & 1.06 & 10199 & 15.3 & 1.08 & 169 & 0.25 & 0.51 \\
\hline & & & & 15.3 to 15.9 & 1.03 to 1.09 & & 15.0 to 15.6 & 1.05 to 1.11 & & 0.22 to 0.30 & 0.42 to 0.62 \\
\hline
\end{tabular}




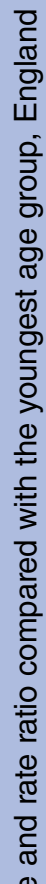

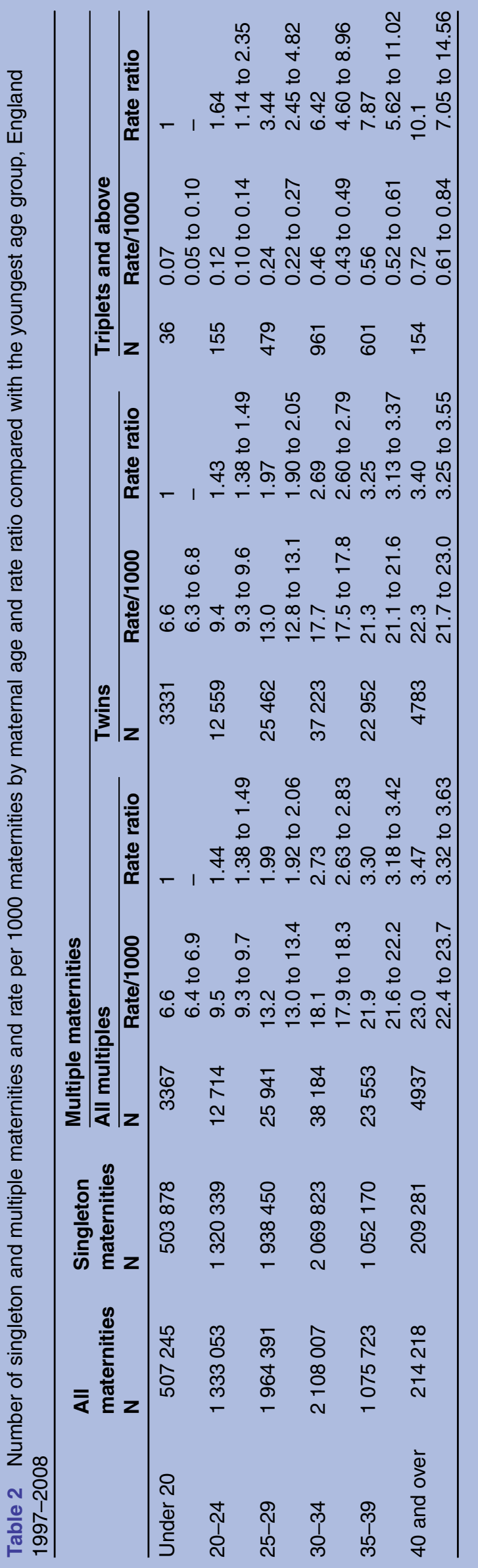

improvement for neonatal mortality among singletons but a greater absolute improvement among twins, since the rates were much higher.

\section{DISCUSSION}

\section{Main findings}

We have shown a continued trend of increasing multiple pregnancies in England, in terms of rates and absolute numbers of deliveries. The findings highlight that this is due to an increase in the rate of twin maternities over the past 12 years. In contrast, the rate of triplets and higher order maternities has halved. Substantial differences were seen by socioeconomic deprivation with a lower rate of multiple births among women from the most deprived areas and this was most evident among women over 35 years of age. Stillbirth rates have fallen considerably among twin births unlike the static picture seen for singletons. The recent improvements also observed in neonatal mortality have benefited singleton and twin births, but wide socioeconomic inequalities exist in mortality for all births.

\section{Possible explanations for findings and comparisons with other work}

The observed reduction in the rate of triplet and higher order births continues the pattern observed by Simmons et at up until 2001, and coincides with changes in the regulatory framework in England governing ART. Although the chances of a successful implantation when undergoing fertility treatments such as in vitro fertilisation (IVF) or gamete intrafallopian transfer treatment is significantly improved by increasing the number of embryos or eggs transferred, multiple births, particularly triplets and higher order pregnancies, are at significantly greater risk of poor outcome compared with singletons. Therefore, in 2001, the Human Fertilisation and Embryology Authority (http://www.hfea.gov.uk/) introduced regulations to limit the transfer of a maximum of two embryos per cycle, except in exceptional circumstances. With sporadic compliance, this policy was tightened further in 2004, so that a maximum of two embryos could be transferred to women under the age of 40 with no exceptions, and a maximum of three transferable to women aged 40 and over. Further evidence suggests that in women under 37 years, elective single embryo transfer is recommended ${ }^{14}$ to improve outcomes. Currently UK fertility units must have a maximum multiple birth rate of $10 \%$ (http://www.hfea. gov.uk/). Our findings of a reduction in the rate of triplet and higher order maternities coincide with these changes in regulation. A possible additional factor influencing the rate of triplets could be the increased frequency of fetal reduction in multifetal pregnancies in the first trimester. In the UK, death of an unborn fetus would not be registered if delivered before 24 weeks of gestation. For those deliveries where a fetal reduction occurred before 24 weeks of gestation and the fetus was 
Figure 1 Rate of multiple maternities per 1000 maternities by year of birth and mother's age.

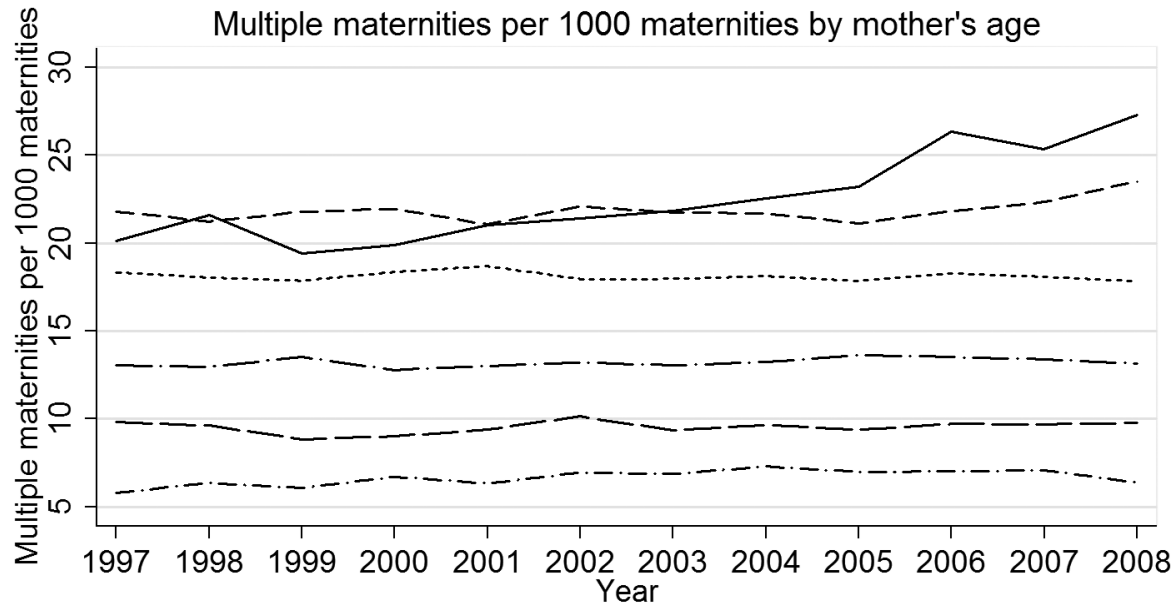

Year

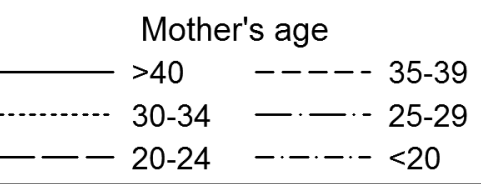

likely to be even greater in those countries where ART is only available privately.

We have observed considerable reductions in stillbirth rates over time for multiple births unlike singletons, where rates have remained static for the last decade. This may relate to the introduction of recommendations for changes in antenatal care, including improved early diagnosis and in utero management of twin-twin transfusion syndrome in monochorionic twins. However, Glinianaia et $a l^{17}$ in a smaller UK regional study found no change in stillbirth rates over time for either monochorionic or dichorionic twins, but monochorionic twins have a considerably higher risk of stillbirth than dichorionic twins predominantly due to twin-twin transfusion syndrome. The apparent improvement in stillbirth rates we have observed may also be partially explained by a change to the proportion of monochorionic versus dichorionic twins over time. Around $16 \%$ of assisted conception multiple pregnancies result in monochorionic twins, ${ }^{18}$ and so a rise in the proportion of multiple births arising from ART would lead to a substantial rise in the proportion of dichorionic twin births. If this is the explanation, it should then be possible to observe an overall reduction in the rate of stillbirth for twins but no improvement in the chorionic specific rates of stillbirth. Since there are no national data on chorionicity, we cannot determine to what extent the changes in stillbirth rates are related to changes in the proportion of monochorionic twins or to actual improvements in care. However, stillbirth rates for twin births improved across all deprivation groups and so it is likely that multiple factors contributed to the observed change in stillbirth rates.

Compared to singletons, there was a smaller deprivation gap in the rate of stillbirth and neonatal death for twins and no significant deprivation gap for triplets and 


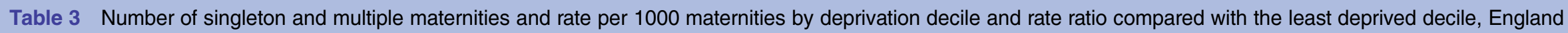
1997-2008

\begin{tabular}{|c|c|c|c|c|c|c|c|c|c|c|c|}
\hline \multirow{3}{*}{$\begin{array}{l}\text { Deprivation } \\
\text { decile (1=least } \\
\text { deprived) }\end{array}$} & \multirow{3}{*}{$\begin{array}{l}\text { All } \\
\text { maternities }\end{array}$} & \multirow{3}{*}{$\begin{array}{l}\text { Singleton } \\
\text { maternities }\end{array}$} & \multicolumn{9}{|c|}{ Multiple maternities } \\
\hline & & & \multicolumn{3}{|c|}{ All multiples } & \multicolumn{3}{|l|}{ Twins } & \multicolumn{3}{|c|}{ Triplets and above } \\
\hline & & & $\mathbf{N}$ & Rate/1000 & Rate ratio & $\bar{N}$ & Rate/1000 & Rate ratio & $\overline{\mathbf{N}}$ & Rate/1000 & Rate ratio \\
\hline \multirow[t]{2}{*}{1} & 720135 & 707142 & 12993 & 18.0 & 1 & 12681 & 17.6 & 1 & 312 & 0.43 & 1 \\
\hline & & & & 17.7 to 18.4 & - & & 17.3 to 17.9 & - & & 0.39 to 0.48 & - \\
\hline \multirow[t]{2}{*}{2} & 718363 & 705833 & 12530 & 17.4 & 0.97 & 12175 & 16.9 & 0.96 & 355 & 0.49 & 1.14 \\
\hline & & & & 17.1 to 17.8 & 0.94 to 0.99 & & 16.6 to 17.3 & 0.94 to 0.99 & & 0.45 to 0.55 & 0.98 to 1.33 \\
\hline \multirow[t]{2}{*}{3} & 720421 & 708292 & 12129 & 16.8 & 0.93 & 11826 & 16.4 & 0.93 & 303 & 0.42 & 0.97 \\
\hline & & & & 16.5 to 17.1 & 0.91 to 0.96 & & 16.1 to 16.7 & 0.91 to 0.96 & & 0.38 to 0.47 & 0.83 to 1.14 \\
\hline \multirow[t]{2}{*}{4} & 721281 & 709734 & 11547 & 16.0 & 0.89 & 11270 & 15.6 & 0.89 & 277 & 0.38 & 0.89 \\
\hline & & & & 15.7 to 16.3 & 0.87 to 0.91 & & 15.3 to 15.9 & 0.87 to 0.91 & & 0.34 to 0.43 & 0.75 to 1.04 \\
\hline \multirow[t]{2}{*}{5} & 722794 & 711547 & 11247 & 15.6 & 0.86 & 11015 & 15.2 & 0.87 & 232 & 0.32 & 0.74 \\
\hline & & & & 15.3 to 15.9 & 0.84 to 0.88 & & 15.0 to 15.5 & 0.84 to 0.89 & & 0.28 to 0.37 & 0.63 to 0.88 \\
\hline \multirow[t]{2}{*}{6} & 721632 & 710992 & 10640 & 14.7 & 0.82 & 10407 & 14.4 & 0.82 & 233 & 0.32 & 0.75 \\
\hline & & & & 14.5 to 15.0 & 0.80 to 0.84 & & 14.1 to 14.7 & 0.80 to 0.84 & & 0.28 to 0.37 & 0.63 to 0.88 \\
\hline \multirow[t]{2}{*}{7} & 720952 & 710806 & 10146 & 14.1 & 0.78 & 9964 & 13.8 & 0.78 & 182 & 0.25 & 0.58 \\
\hline & & & & 13.8 to 14.3 & 0.76 to 0.80 & & 13.6 to 14.1 & 0.76 to 0.81 & & 0.22 to 0.29 & 0.49 to 0.70 \\
\hline \multirow[t]{2}{*}{8} & 718171 & 708591 & 9580 & 13.3 & 0.74 & 9383 & 13.1 & 0.74 & 197 & 0.27 & 0.63 \\
\hline & & & & 13.1 to 13.6 & 0.72 to 0.76 & & 12.8 to 13.3 & 0.72 to 0.76 & & 0.24 to 0.32 & 0.53 to 0.76 \\
\hline \multirow[t]{2}{*}{9} & 716909 & 707727 & 9182 & 12.8 & 0.71 & 9031 & 12.6 & 0.72 & 151 & 0.21 & 0.49 \\
\hline & & & & 12.5 to 13.1 & 0.69 to 0.73 & & 12.3 to 12.9 & 0.70 to 0.73 & & 0.18 to 0.25 & 0.40 to 0.59 \\
\hline \multirow[t]{2}{*}{10} & 721979 & 713277 & 8702 & 12.1 & 0.67 & 8558 & 11.9 & 0.67 & 144 & 0.20 & 0.46 \\
\hline & & & & 11.8 to 12.3 & 0.65 to 0.69 & & 11.6 to 12.1 & 0.65 to 0.69 & & 0.17 to 0.23 & 0.38 to 0.56 \\
\hline
\end{tabular}

Table 4 Stillbirth and neonatal mortality: numbers and rate per 10000 births by multiplicity and year of birth, England 1997-2008

\begin{tabular}{|c|c|c|c|c|c|c|c|c|c|c|}
\hline \multirow[b]{3}{*}{ Year of birth } & \multirow{2}{*}{\multicolumn{2}{|c|}{ Live births }} & \multirow{2}{*}{\multicolumn{2}{|c|}{ Stillbirths }} & \multirow{2}{*}{\multicolumn{2}{|c|}{ Neonatal death }} & \multicolumn{4}{|c|}{ Rate/10 000 births } \\
\hline & & & & & & & \multicolumn{2}{|c|}{ Stillbirths } & \multicolumn{2}{|c|}{ Neonatal death } \\
\hline & Singleton & Twins & Singleton & Twins & Singleton & Twins & Singleton & Twins & Singleton & Twins \\
\hline \multirow[t]{2}{*}{ 1997-2000 } & 2305156 & 65203 & 9869 & 812 & 6798 & 1222 & 42.6 & 123.0 & 29.5 & 187.4 \\
\hline & & & & & & & 41.8 to 43.5 & 114.8 to 131.8 & 28.8 to 30.2 & 177.2 to 198.2 \\
\hline \multirow[t]{2}{*}{ 2001-2004 } & 2258773 & 66786 & 9947 & 713 & 5997 & 1098 & 43.8 & 105.6 & 26.6 & 164.4 \\
\hline & & & & & & & 43.0 to 44.7 & 98.2 to 113.7 & 25.9 to 27.2 & 155.0 to 174.4 \\
\hline \multirow[t]{2}{*}{ 2005-2008 } & 2499891 & 76230 & 10305 & 702 & 5970 & 1164 & 41.1 & 91.2 & 23.9 & 152.7 \\
\hline & & & & & & & 40.3 to 41.9 & 84.7 to 98.3 & 23.3 to 24.5 & 144.2 to 161.7 \\
\hline
\end{tabular}


Figure 2 (A and B) Rate of multiple maternities per 100 maternities over time by mother's age from the least and most deprived deciles of deprivation.
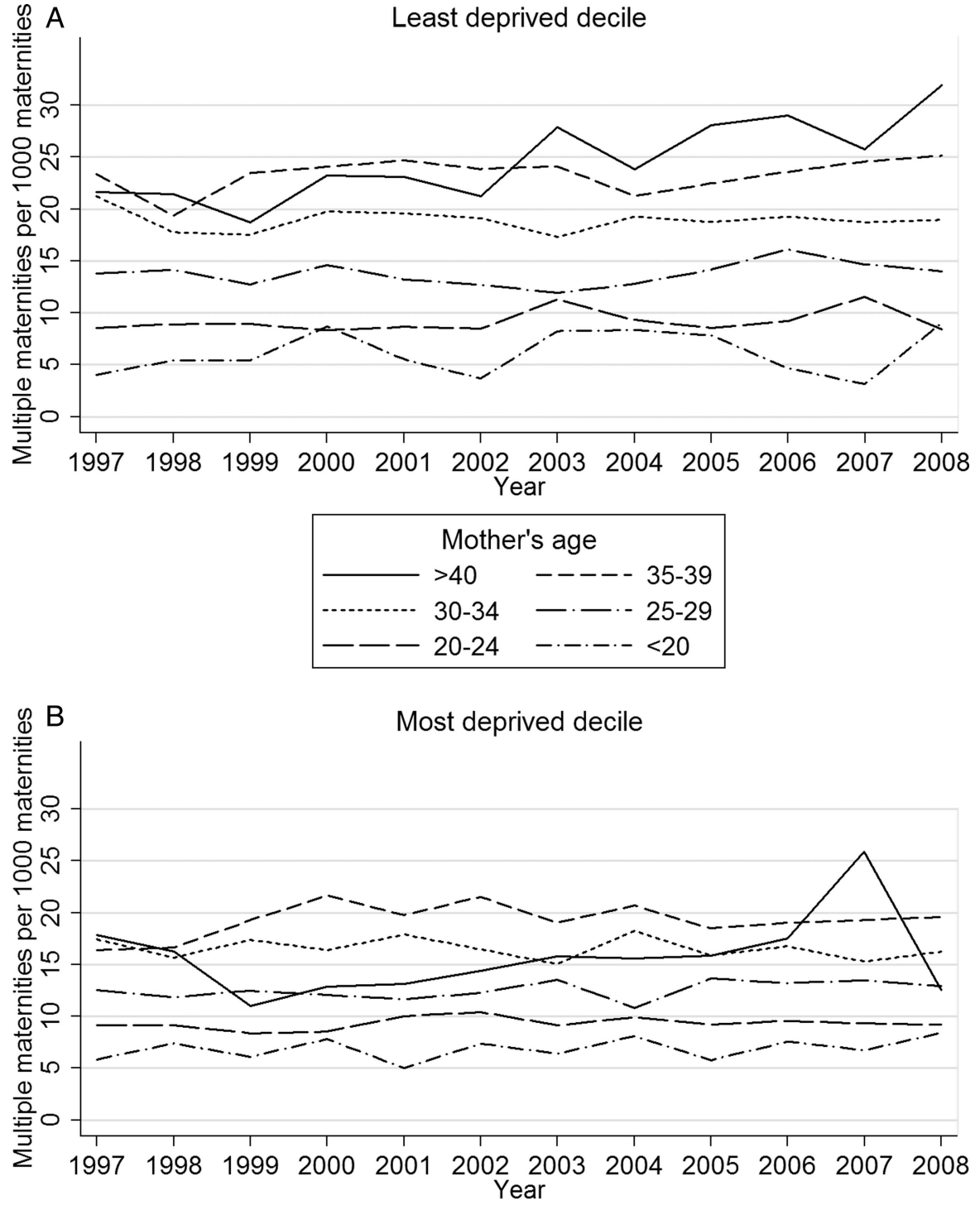

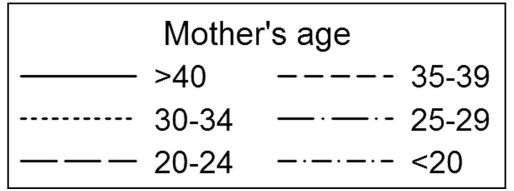

higher order births. However, the absolute deprivation gap was wider. Research on explanations for the deprivation gap in neonatal mortality among singleton births has shown that it is predominantly explained by increased rates of prematurity and its associated complications. ${ }^{19}$ Multiple births are at much higher risk of prematurity with the rate of preterm birth ( $<37$ weeks gestation) being 10 times higher among multiple births and with half of all multiple births being born at these gestations. ${ }^{11}$ Intrauterine growth restriction is also associated with deprivation ${ }^{20}$ and increased complications of prematurity. However, it is suggested that small-size and premature delivery in the case of multiple births may be more related to physiological adaptation to the more limited intrauterine environment ${ }^{21}$ in contrast to the proposed mechanisms in singleton births where maternal or fetal pathology is often implicated. Without further research, it is not possible to estimate the extent to which prematurity is responsible for the deprivation gap in neonatal deaths among multiple births.

\section{Strengths and limitations}

This study uses national routinely collected data to evaluate trends in multiple birth rates. These data have the advantage of being readily available and having national coverage. They lack detail on the chorionicity of the multiple births and so differences in trends could not be investigated between monochorionic and dichorionic twins. While the focus of increased twinning has been associated with dichorionic twins relating to assisted conception techniques, data are now indicating that these techniques also lead to increases in monochorionic 
Table 5 Stillbirth and neonatal mortality: numbers and rate per 10000 births by multiplicity and deprivation decile, England 1997-2008

\begin{tabular}{|c|c|c|c|c|c|c|c|c|c|c|}
\hline \multirow{3}{*}{$\begin{array}{l}\text { Decile of } \\
\text { deprivation }\end{array}$} & \multirow{2}{*}{\multicolumn{2}{|c|}{ Live births }} & \multirow{2}{*}{\multicolumn{2}{|c|}{ Stillbirths }} & \multirow{2}{*}{\multicolumn{2}{|c|}{ Neonatal death }} & \multicolumn{4}{|c|}{ Rate/10 000 births } \\
\hline & & & & & & & \multicolumn{2}{|c|}{ Stillbirths } & \multicolumn{2}{|c|}{ Neonatal death } \\
\hline & Singleton & Twins & Singleton & Twins & Singleton & Twins & Singleton & Twins & Singleton & Twins \\
\hline \multirow[t]{2}{*}{1} & 705052 & 24951 & 2090 & 221 & 1147 & 290 & 29.6 & 87.8 & 16.3 & 116.2 \\
\hline & & & & & & & 28.3 to 20.9 & 77.0 to 100.2 & 15.4 to 17.2 & 103.6 to 130.4 \\
\hline \multirow[t]{2}{*}{2} & 703622 & 23923 & 2211 & 211 & 1334 & 340 & 31.3 & 87.4 & 19.0 & 142.1 \\
\hline & & & & & & & 30.0 to 32.7 & 76.4 to 100.1 & 18.0 to 20.0 & 127.8 to 158.1 \\
\hline \multirow[t]{2}{*}{3} & 705970 & 23259 & 2322 & 219 & 1454 & 323 & 32.8 & 93.3 & 20.6 & 138.9 \\
\hline & & & & & & & 31.5 to 34.1 & 81.7 to 106.5 & 19.6 to 21.7 & 124.5 to 154.9 \\
\hline \multirow[t]{2}{*}{4} & 707133 & 22112 & 2601 & 222 & 1640 & 320 & 36.6 & 99.4 & 23.2 & 144.7 \\
\hline & & & & & & & 35.3 to 38.1 & 85.9 to 112.3 & 22.1 to 24.3 & 129.7 to 161.5 \\
\hline \multirow[t]{2}{*}{5} & 708703 & 21571 & 2844 & 214 & 1653 & 366 & 40.0 & 98.2 & 23.3 & 169.7 \\
\hline & & & & & & & 38.5 to 41.5 & 85.9 to 112.3 & 22.2 to 24.5 & 153.2 to 188.0 \\
\hline \multirow[t]{2}{*}{6} & 707961 & 20362 & 3031 & 223 & 1865 & 363 & 42.6 & 108.3 & 26.3 & 178.3 \\
\hline & & & & & & & 41.1 to 44.2 & 95.0 to 12.35 & 25.2 to 27.6 & 160.8 to 197.6 \\
\hline \multirow[t]{2}{*}{7} & 707436 & 19449 & 3370 & 249 & 2093 & 365 & 47.4 & 126.4 & 29.6 & 178.7 \\
\hline & & & & & & & 45.8 to 49.0 & 111.6 to 143.1 & 28.3 to 30.9 & 169.4 to 207.9 \\
\hline \multirow[t]{2}{*}{8} & 704896 & 18318 & 3695 & 220 & 2274 & 378 & 52.1 & 118.7 & 32.3 & 206.4 \\
\hline & & & & & & & 50.5 to 53.9 & 104.0 to 135.4 & 31.0 to 33.6 & 186.6 to 228.2 \\
\hline \multirow[t]{2}{*}{9} & 703868 & 17611 & 3859 & 220 & 2521 & 364 & 54.5 & 123.4 & 35.8 & 206.7 \\
\hline & & & & & & & 52.8 to 56.3 & 108.1 to 140.8 & 34.4 to 37.2 & 186.5 to 229.1 \\
\hline \multirow[t]{2}{*}{10} & 709179 & 16663 & 4098 & 228 & 2784 & 375 & 57.5 & 135.0 & 39.3 & 225.1 \\
\hline & & & & & & & 55.7 to 59.2 & 118.6 to 153.7 & 37.8 to 40.7 & 203.4 to 249.0 \\
\hline
\end{tabular}




\begin{tabular}{|c|c|c|c|c|c|c|c|c|c|c|c|}
\hline \multirow[b]{3}{*}{ Year of birth } & \multirow[b]{3}{*}{ Deprivation decile } & \multirow{2}{*}{\multicolumn{2}{|c|}{ Live births }} & \multirow{2}{*}{\multicolumn{2}{|c|}{ Stillbirths }} & \multirow{2}{*}{\multicolumn{2}{|c|}{ Neonatal death }} & \multicolumn{4}{|c|}{ Rate/10 000 births } \\
\hline & & & & & & & & \multicolumn{2}{|c|}{ Stillbirths } & \multicolumn{2}{|c|}{ Neonatal death } \\
\hline & & Singleton & Twins & Singleton & Twins & Singleton & Twins & Singleton & Twins & Singleton & Twins \\
\hline \multirow[t]{19}{*}{ 1997-2000 } & 1 least deprived & 239290 & 8047 & 709 & 73 & 442 & 96 & $\begin{array}{l}29.5 \\
27.4 \text { to } 31.8\end{array}$ & $\begin{array}{l}89.9 \\
71.5 \text { to } 113.1\end{array}$ & $\begin{array}{l}18.5 \\
16.8 \text { to } 20.3\end{array}$ & $\begin{array}{l}119.3 \\
97.7 \text { to } 145.7\end{array}$ \\
\hline & 2 & 235080 & 7567 & 790 & 74 & 540 & 119 & 33.5 & 96.8 & 23.0 & 157.3 \\
\hline & & & & & & & & 31.2 to 35.9 & 77.1 to 121.6 & 21.1 to 25.0 & 131.4 to 188.2 \\
\hline & 3 & 235371 & 7261 & 794 & 83 & 550 & 106 & 33.6 & 113.0 & 23.4 & 146.0 \\
\hline & & & & & & & & 31.4 to 36.0 & 91.1 to 140.1 & 21.5 to 25.4 & 120.7 to 176.6 \\
\hline & 4 & 233135 & 7132 & 869 & 102 & 620 & 116 & 37.1 & 141.0 & 26.6 & 162.6 \\
\hline & & & & & & & & 34.7 to 39.7 & 116.1 to 171.2 & 24.6 to 28.8 & 135.6 to 195.1 \\
\hline & 5 & 232029 & 6723 & 906 & 83 & 617 & 146 & 38.9 & 122.0 & 26.6 & 217.2 \\
\hline & & & & & & & & 36.4 to 41.5 & 98.3 to 151.2 & 24.6 to 28.8 & 184.6 to 255.4 \\
\hline & 6 & 228561 & 6348 & 1028 & 76 & 652 & 132 & 44.8 & 118.3 & 28.5 & 207.9 \\
\hline & & & & & & & & 42.1 to 47.6 & 94.5 to 148.1 & 26.4 to 30.8 & 175.3 to 246.6 \\
\hline & 7 & 225246 & 5966 & 1066 & 87 & 738 & 130 & 47.1 & 143.7 & 32.8 & 217.9 \\
\hline & & & & & & & & 44.4 to 50.0 & 116.5 to 177.3 & 30.5 to 35.2 & 183.5 to 258.8 \\
\hline & 8 & 223839 & 5580 & 1146 & 81 & 770 & 143 & 50.9 & 143.1 & 34.4 & 256.3 \\
\hline & & & & & & & & 48.1 to 54.0 & 115.1 to 177.9 & 32.1 to 36.9 & 217.5 to 301.9 \\
\hline & 9 & 223662 & 5454 & 1240 & 76 & 863 & 111 & 55.1 & 137.4 & 38.6 & 203.5 \\
\hline & & & & & & & & 52.2 to 58.3 & 109.8 to 172.1 & 36.1 to 41.2 & 169.0 to 245.1 \\
\hline & 10 most deprived & 228943 & 5125 & 1321 & 77 & 1006 & 123 & 57.4 & 148.0 & 43.9 & 240.0 \\
\hline & & & & & & & & 54.4 to 60.5 & 118.4 to 185.1 & 41.3 to 46.7 & 201.1 to 286.4 \\
\hline \multirow[t]{18}{*}{ 2001-2004 } & 1 least deprived & 228780 & 8021 & 709 & 84 & 360 & 105 & 30.9 & 103.6 & 15.7 & 130.9 \\
\hline & & & & & & & & 28.7 to 33.3 & 83.7 to 128.4 & 14.2 to 17.4 & 108.1 to 158.5 \\
\hline & 2 & 227883 & 7848 & 702 & 71 & 411 & 105 & 30.7 & 89.7 & 18.0 & 133.7 \\
\hline & & & & & & & & 28.5 to 33.1 & 71.1 to 113.1 & 16.4 to 19.9 & 110.5 to 162.0 \\
\hline & 3 & 227298 & 7543 & 777 & 69 & 421 & 92 & 34.1 & 90.6 & 18.5 & 122.0 \\
\hline & & & & & & & & 31.8 to 36.5 & 71.6 to 114.8 & 16.8 to 20.4 & 99.4 to 149.6 \\
\hline & 4 & 226108 & 7065 & 811 & 56 & 539 & 103 & 35.7 & 78.6 & 23.8 & 145.8 \\
\hline & & & & & & & & 33.4 to 38.3 & 60.5 to 102.2 & 21.9 to 25.9 & 120.2 to 176.8 \\
\hline & 5 & 225135 & 6985 & 934 & 69 & 500 & 110 & 41.3 & 97.8 & 22.2 & 157.5 \\
\hline & & & & & & & & 38.7 to 44.1 & 77.3 to 123.8 & 20.3 to 24.2 & 130.6 to 189.8 \\
\hline & 6 & 224169 & 6413 & 952 & 67 & 602 & 103 & 42.3 & 103.4 & 26.9 & 160.6 \\
\hline & & & & & & & & 39.7 to 45.1 & 81.4 to 131.4 & 24.8 to 29.1 & 132.4 to 194.8 \\
\hline & 7 & 223600 & 6293 & 1129 & 84 & 664 & 111 & 50.2 & 131.7 & 29.7 & 176.4 \\
\hline & & & & & & & & 47.4 to 53.3 & 106.4 to 163.1 & 27.5 to 32.0 & 146.4 to 212.5 \\
\hline & 8 & 224048 & 5738 & 1249 & 67 & 769 & 121 & 55.4 & 115.4 & 34.3 & 210.9 \\
\hline & & & & & & & & 52.4 to 58.6 & 90.8 to 146.6 & 32.0 to 36.8 & 176.5 to 252.0 \\
\hline & 9 & 225700 & 5543 & 1295 & 70 & 839 & 126 & 57.1 & 124.7 & 37.2 & 227.3 \\
\hline & & & & & & & & 54.0 to 60.2 & 98.7 to 157.6 & 34.7 to 39.8 & 190.9 to 270.7 \\
\hline
\end{tabular}




\begin{tabular}{|c|c|c|c|c|c|c|c|c|c|c|c|}
\hline \multirow[b]{3}{*}{ Year of birth } & \multirow[b]{3}{*}{ Deprivation decile } & & & & & & & \multicolumn{4}{|c|}{ Rate/10 000 births } \\
\hline & & \multicolumn{2}{|l|}{ Live births } & \multicolumn{2}{|l|}{ Stillbirths } & \multicolumn{2}{|c|}{ Neonatal death } & \multicolumn{2}{|c|}{ Stillbirths } & \multicolumn{2}{|c|}{ Neonatal death } \\
\hline & & Singleton & Twins & Singleton & Twins & Singleton & Twins & Singleton & Twins & Singleton & Twins \\
\hline & 10 most deprived & 226052 & 5337 & 1389 & 76 & 892 & 122 & 61.1 & 140.4 & 39.5 & 228.6 \\
\hline & & & & & & & & 57.9 to 64.4 & 112.1 to 175.8 & 37.0 to 42.1 & 191.4 to 273.0 \\
\hline \multirow[t]{20}{*}{ 2005-2008 } & 1 least deprived & 236982 & 8883 & 672 & 64 & 345 & 89 & 28.3 & 71.5 & 14.6 & 100.2 \\
\hline & & & & & & & & 26.2 to 30.5 & 56.0 to 91.4 & 13.1 to 16.2 & 81.4 to 123.3 \\
\hline & 2 & 240659 & 8508 & 719 & 66 & 383 & 116 & 29.8 & 77.0 & 15.9 & 136.3 \\
\hline & & & & & & & & 27.7 to 32.0 & 60.5 to 98.0 & 14.4 to 17.6 & 113.6 to 163.6 \\
\hline & 3 & 243301 & 8455 & 751 & 67 & 483 & 125 & 30.8 & 78.6 & 19.9 & 147.8 \\
\hline & & & & & & & & 28.6 to 33.1 & 61.9 to 99.9 & 18.2 to 21.7 & 124.1 to 176.2 \\
\hline & 4 & 247890 & 7915 & 921 & 64 & 481 & 101 & 37.0 & 80.2 & 19.4 & 127.6 \\
\hline & & & & & & & & 34.7 to 39.5 & 62.8 to 102.5 & 17.7 to 21.2 & 105.0 to 155.1 \\
\hline & 5 & 251539 & 7863 & 1004 & 62 & 536 & 110 & 39.8 & 78.2 & 21.3 & 139.9 \\
\hline & & & & & & & & 37.4 to 42.3 & 61.0 to 100.3 & 19.6 to 23.2 & 116.1 to 168.6 \\
\hline & 6 & 255231 & 7601 & 1051 & 80 & 611 & 128 & 41.0 & 104.2 & 23.9 & 168.4 \\
\hline & & & & & & & & 38.6 to 43.6 & 83.7 to 129.7 & 22.1 to 25.9 & 141.6 to 200.3 \\
\hline & 7 & 258590 & 7190 & 1175 & 78 & 691 & 124 & 45.2 & 107.3 & 26.7 & 172.5 \\
\hline & & & & & & & & 42.7 to 47.9 & 86.0 to 134.0 & 24.8 to 28.8 & 144.6 to 205.7 \\
\hline & 8 & 257009 & 7000 & 1300 & 72 & 735 & 114 & 50.3 & 101.8 & 28.6 & 162.9 \\
\hline & & & & & & & & 47.7 to 53.1 & 80.8 to 128.3 & 26.6 to 30.7 & 135.5 to 195.7 \\
\hline & 9 & 254506 & 6614 & 1324 & 74 & 819 & 127 & 51.8 & 110.6 & 32.2 & 192.0 \\
\hline & & & & & & & & 49.0 to 54.6 & 88.1 to 139.0 & 30.1 to 34.5 & 161.4 to 228.5 \\
\hline & 10 most deprived & 254184 & 6201 & 1388 & 75 & 886 & 130 & 54.3 & 119.5 & 34.9 & 209.6 \\
\hline & & & & & & & & 51.5 to 57.2 & 95.3 to 149.9 & 32.6 to 37.2 & 176.5 to 249.0 \\
\hline
\end{tabular}

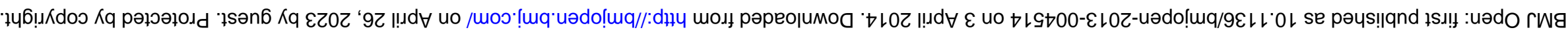


twins and outcomes in these twins are particularly poor. ${ }^{17}$ We also did not have information on the use of ART. While information on chorionicity and the use of ART is not currently available nationally, data collection on these factors will start from January 2013 as part of the MBRRACE-UK programme. This will provide a national picture of chorionicity and ART among stillbirths and infant deaths in the future.

The data we obtained did not link births from the same maternity. Consequently, we had to estimate the number of multiple maternities which is prone to error as a result of a lack of data on late fetal losses. Similarly, early selective feticide for congenital anomalies may lead to misclassification of some multiple pregnancies as singleton births. However, our sensitivity analyses comparing the overall estimated number of multiple maternities with published data showed that this method estimated the overall number to within $1 \%$ of the actual rates and so any impact on the findings presented here is likely to be small. Unfortunately, in the analysis of stillbirths and neonatal deaths, we could not take account of the correlated nature of the outcomes of multiple births from the same pregnancy. The CIs presented here are consequently likely to have been narrower had this adjustment been possible, but this is unlikely to have impacted on our conclusions. National data were also unavailable on gestational age for this time period which prevented exploration or adjustment of mortality for prematurity. Furthermore, while national published data are available, they do not offer the ability to explore interactions between risk factors.

\section{Implications and future research needs}

The continuing rise in multiple birth rates and overall increases in births over the past 12 years has had a large impact on the absolute numbers of twin and triplets delivered in England. While there has been a reduction in the rate of triplet and higher order births, which are the most at risk of neonatal death, there are now around 1300 more multiple births a year in England compared with 1997. Since over half of all multiple births are born prematurely, ${ }^{11}$ increasing healthcare provision and NHS costs for neonatal and longer term care arising from this group of babies will ensue. These high risks for multiple births support the policies in place to reduce the rate of multiple births in the UK and the need to consider reviewing the practice of allowing multiple egg or embryo transfer in older women.

Current national data prevent detailed exploration of socioeconomic inequalities in access to ART in England. However, recently established procedures for national data collection of this information will enable monitoring of such trends in the future. This will also permit an assessment of whether recent changes in the guidelines for provision of assisted conception techniques in the UK, increasing the permitted number of cycles open to women under 39 years, have led to improved access to ART services across all socioeconomic groups.
Acknowledgements The authors would like to thank members of The Infant Mortality and Morbidity Studies team (University of Leicester) for helpful advice and comments throughout the study.

Contributors LKS, DJF and ESD conceived the study idea and designed the study. LKS analysed and interpreted the data with help from BNM. DJF, ESD, SJJ and EMB contributed to interpretation of the data. LKS wrote a first draft of the manuscript, and all coauthors critically revised the manuscript. The guarantor is LKS.

Funding This article presents independent research funded by the National Institute for Health Research (NIHR) under its Programme Grants for Applied Research (PGfAR) programme (grant reference number RP-PG-0407-10029).

\section{Competing interests None.}

Provenance and peer review Not commissioned; externally peer reviewed.

Data sharing statement No additional data are available from the authors but may be obtained from ONS.

Open Access This is an Open Access article distributed in accordance with the Creative Commons Attribution Non Commercial (CC BY-NC 3.0) license, which permits others to distribute, remix, adapt, build upon this work noncommercially, and license their derivative works on different terms, provided the original work is properly cited and the use is non-commercial. See: http:// creativecommons.org/licenses/by-nc/3.0/

\section{REFERENCES}

1. Collins J. Global epidemiology of multiple birth. Reprod Biomed Online 2007;15(Suppl 30):45-52.

2. Dunn A, Macfarlane A. Recent trends in the incidence of multiple births and associated mortality in England and Wales. Arch Dis Child Fetal Neonatal Ed 1996;75:F10-19.

3. Botting BJ, Davies IM, Macfarlane AJ. Recent trends in the incidence of multiple births and associated mortality. Arch Dis Child 1987;62:941-50.

4. Blondel B, Macfarlane A, Gissler M, et al. Preterm birth and multiple pregnancy in European countries participating in the PERISTAT project. BJOG 2006;113:528-35.

5. Fell DB, Joseph K. Temporal trends in the frequency of twins and higher-order multiple births in Canada and the United States. BMC Pregnancy Childbirth 2012;12:103.

6. Simmons R, Doyle P, Maconochie N. Dramatic reduction in triplet and higher order births in England and Wales. BJOG 2004;111:856-8.

7. Tucker J, McGuire W. Epidemiology of preterm birth. BMJ 2004;329:675-8.

8. Field D. Impact of twins on neonatal care. In: Kilby M, Baker P, Critchley HField D. eds. Multiple pregnancy. London: RCOG Press, 2006:139-48.

9. Yamamoto M, Ville $\mathrm{Y}$. Twin-to-twin transfusion syndrome. In: Kilby MD, Baker P, Critchley H, Field D. eds. Multiple pregnancy. London: RCOG, 2006:183-98.

10. Edwards MS, Ellings JM, Newman RB, et al. Predictive value of antepartum ultrasound examination for anomalies in twin gestations. Ultrasound Obstet Gynecol 1995;6:43-9.

11. Office for National Statistics. Gestation-specific infant mortality in England and Wales, 2010. London, 2012.

12. Maher J, Macfarlane A. Trends in live births and birthweight by social class, marital status and mother's age, 1976-2000. Health Stat Q 2004:34-42

13. Neighbourhood Renewal Unit. The English indices of deprivation 2004 (revised). London: Neighbourhood Renewal Unit, Office for the Deputy Prime Minister, 2004.

14. Scotland GS, McLernon D, Kurinczuk JJ, et al. Minimising twins in in vitro fertilisation: a modelling study assessing the costs, consequences and cost-utility of elective single versus double embryo transfer over a 20 -year time horizon. BJOG 2011;118:1073-83.

15. Carson C, Kelly Y, Kurinczuk JJ, et al. Effect of pregnancy planning and fertility treatment on cognitive outcomes in children at ages 3 and 5: longitudinal cohort study. BMJ 2011;343:d4473.

16. National Institute for Health and Care Excellence. Fertility: assessment and treatment for people with fertility problems; NICE clinical guideline 156. Manchester, 2013.

17. Glinianaia SV, Obeysekera MA, Sturgiss S, et al. Stillbirth and neonatal mortality in monochorionic and dichorionic twins: a population-based study. Hum Reprod 2011;26:2549-57. 
18. Platt MJ, Marshall A, Pharoah PO. The effects of assisted reproduction on the trends and zygosity of multiple births in England and Wales 1974-99. Twin Res 2001;4:417-21.

19. Smith LK, Manktelow BN, Draper ES, et al. An investigation of the nature of socioeconomic inequalities in neonatal mortality: a population based study. BMJ 2010;341:c6654.
20. Beard J, Lincoln D, Donoghue D, et al. Socioeconomic and maternal determinants of small-for-gestational age births: patterns of increasing disparity. Acta Obstet Gynecol Scand 2009;88:575-83.

21. Blickstein I, Goldman RD, Mazkereth R. Adaptive growth restriction as a pattern of birth weight discordance in twin gestations. Obstet Gynecol 2000;96:986-90. 